\title{
Stability, frequency and multiplicity of transposon insertions in the pyoverdine region in the chromosomes of different fluorescent pseudomonads
}

\author{
P. Cornelis, ${ }^{1 *}$ V. Anjaiah, ${ }^{1}$ N. Koedam, ${ }^{2}$ P. Delfosse, ${ }^{3}$ P. Jacques,${ }^{3}$ P. Thonart $^{3}$ and \\ L. NEIRINCKX ${ }^{2}$ \\ ${ }^{1}$ Laboratorium Algemene Biologie, Vrije Universiteit Brussel, Paardenstraat 65, B-1640 St-Genesius Rode, Belgium \\ ${ }^{2}$ Laboratorium Plantenfysiologie, Vrije Universiteit Brussel, Paardenstraat 65, B-1640 St-Genesius Rode, Belgium \\ ${ }^{3}$ Centre Wallon de Biologie Industrielle, Service de Technologie Microbienne, Université de Liège, Sart Tilman B 40, \\ B-4000 Liège, Belgium
}

(Received 4 November 1991; revised 18 February 1992; accepted 9 April 1992)

\begin{abstract}
Tn5 mutagenesis of different fluorescent pseudomonads was achieved by conjugational transfer of the suicide vector pSUP 10141. Pyoverdine negative ( $\mathrm{Pvd}^{-}$) mutants were detected by the absence of fluorescence on King's B medium and by their inability to grow in the presence of the iron chelator EDDHA lethylenediamine di(ohydroxyphenylacetic acid)]. In $P$. fluorescens ATCC 17400 and three rhizosphere isolates (one $P$. putida and two $P$. fluorescens), the percentage of Pvd- mutants ranged between 0 and $0.54 \%$. In a $P$. chlororaphis rhizosphere isolate, this percentage was higher (4\%). In these mutants both of the $\mathrm{Tn} 5$ antibiotic resistances (Km and $\mathrm{Tc}$ ) were stable and the transposon could be detected by hybridization. In Pvd ${ }^{-}$mutants of $P$. fluorescens ATCC 17400, the transposon was found to be inserted twice in the chromosome while single insertions were detected in the DNA of other, randomly tested mutants. In $P$. aeruginosa PAO1, where $13.1 \%$ of the mutants were Pvd $^{-}$, both antibiotic resistances were rapidly lost and accordingly no transposon insertion could be detected by hybridization. However, the $\mathrm{Pvd}^{-}$phenotype was generally stable in these mutants. The plasmid pNK862 containing a mini-Tn10 transposon was introduced by electroporation into $P$. aeruginosa $\mathrm{PAO1}$ and $\mathrm{Km}^{\mathrm{r}}$ mutants were recovered, $89 \%$ of which were $\mathrm{Pvd}^{-}$and confirmed to be $P$. aeruginosa by PCR amplification of the $P$. aeruginosa lipoprotein gene. The mini-Tn10 insertions were also found to be unstable in PAO1.
\end{abstract}

\section{Introduction}

Transposon mutagenesis of Gram-negative bacteria by conjugational transfer of suicide vectors is a very powerful technique presenting many advantages compared to other techniques (UV irradiation and chemical mutagenesis) such as single gene inactivation, and stability and possibility of cloning the mutated gene (Kleckner, 1981). Among the different available transposons, $\operatorname{Tn} 5$ has been the most widely used for obtaining mutants in different Gram-negative bacteria (Berg \& Berg, 1983). The main advantages of $\operatorname{Tn} 5$ are its relative randomness of insertion (Berg, 1977) and its ability to

\footnotetext{
* Author for correspondence. Tel. 2 3590258; fax. 23590390
}

Abbreviation: EDDHA, ethylenediamine di(o-hydroxyphenylacetic acid). function in different hosts. There have already been several reports on the successful use of $\operatorname{Tn} 5$ for generating mutants, in particular $\mathrm{Pvd}^{-}$mutants in several fluorescent pseudomonads (Marugg et al., 1985; O'Sullivan \& O'Gara, 1990), including a rhizosphere strain of $P$. aeruginosa (Höfte et al., 1991). However, Goldberg et al. (1990) recently described the instability and precise excision of $\mathrm{Tn} 5$ in $P$. aeruginosa. These authors demonstrated that only the long terminal inverted repeats were needed to cause the excision, without involvement of the transposase. We were interested to see whether this instability was specific for $\operatorname{Tn} 5$ or whether, as suggested by these authors, it is the result of an adaptation of $P$. aeruginosa to eliminate composite transposons from its genome. High affinity iron uptake in fluorescent pseudomonads is mediated by pyoverdine or pseudobactin, a complex fluorescent 
siderophore made of a catecholate chromophore and a peptide arm of variable length and composition containing unusual amino acids (Wendenbaum et al., 1983, Hohnadel \& Meyer, 1988). Both catechol groups from the chromophore and hydroxamate or hydroxycarboxylate groups provided by the unusual amino acids $\delta$ - Nhydroxyornithine or $\beta$-hydroxyaspartic acid respectively (depending on the pyoverdine) participate in complexing Fe(III) (Hohnadel \& Meyer, 1988). Mutants in the biosynthesis of the siderophore are easy to detect either by their lack of fluorescence (Flu $\left.{ }^{-}\right)$in iron-limited media and/or by their inability to grow (EDDHA ${ }^{-}$) in the presence of the iron chelator ethylenediamine $\operatorname{di}(o-$ hydroxyphenylacetic acid). Our interests focus on the regulation of pyoverdine biosynthesis in different fluorescent pseudomonads and on the role of pyoverdine in the antagonism shown by some strains in this group of bacteria against fungal pathogens like Pythium and Fusarium (Leong, 1986). We show here that in $P$. aeruginosa, $\mathrm{Tn} 5$ and mini-Kan $\mathrm{Tn} 10$ are unstable and yield an unusually high percentage of $\mathrm{Pvd}^{-}$mutants.

\section{Methods}

Bacterial strains and plasmids. Pseudomonas aeruginosa PAO1 and Pseudomonas fluorescens ATCC 17400 were obtained from J. M. Meyer (Strasbourg, France). Pseudomonas chlororaphis BTP9, Pseudomonas putida BTP1 and the unidentified fluorescent Pseudomonas strain BTP20 were rhizosphere isolates from the Centre Wallon de Biologie Industrielle (University of Liège, Belgium). Pseudomonas fuorescens strain 47 is an isolate from the rhizosphere of poplar (S. Hettiarachchi, Vrije Universiteit Brussel).

E. coli strain S17-1 (thi pro hsdR-hsdM+recA RP4 2-Tc::Mu$\mathrm{Km}:: \mathrm{Tn} 7 \mathrm{Tp} \mathrm{Sm}$ ) was given by Simon et al. (1983), together with the plasmid pSUP10141 (a pACYC184 derivative with Tn5 inserted into its $\mathrm{Tc}^{r}$ gene and a $4 \mathrm{~kb}$ RP4 Sau3A fragment containing a $\mathrm{Tc}^{r}$ gene cloned in the Tn 5 BamHI site). Plasmid pMMB33 (IncP-4 Mob ${ }^{+} \cos \lambda$ $\mathrm{Km}$ ) was from Frey et al. (1983). Plasmid pNK862 is a derivative of pBR333 containing an EcoRI-PvuII ptac promoter fragment ligated to a blunt made $B c l I$ site of IS 10 right next to a $1.7 \mathrm{~kb} \mathrm{HindIII} \mathrm{Km}^{\mathrm{r}}$ fragment from Tn903 (Way et al., 1984).

Growth media. Bacteria were grown in LB medium. For the screening of $\mathrm{Pvd}^{-}$mutants, modified King's B (MKB) medium was used (Proteose peptone $5 \mathrm{~g} \mathrm{l}^{-1}, \mathrm{MgSO} 4.7 \mathrm{H}_{2} \mathrm{O} 1.5 \mathrm{~g} \mathrm{l}^{-1}, \mathrm{~K}_{2} \mathrm{HPO}_{4} 1.2 \mathrm{~g} \mathrm{l}^{-1}$, glycerol $\left.2 \mathrm{ml} \mathrm{l}^{-1}\right)$. The mutants were further characterized in Casamino acids (CAA) medium (Casamino acids $5 \mathrm{~g} \mathrm{t}^{-1}, \mathrm{~K}_{2} \mathrm{HPO}_{4} 0.9 \mathrm{~g} \mathrm{l}^{-1}$, $\left.\mathrm{MgSO}_{4} .7 \mathrm{H}_{2} \mathrm{O}, 0.25 \mathrm{~g} \mathrm{l}^{-1}\right)$. Antibiotics were used at the following concentrations $\left(\mathrm{ml}^{-1}\right)$ : ampicillin (Ap) $100 \mu \mathrm{g}$; chloramphenicol $(\mathrm{Cm})$ $25 \mu \mathrm{g}$ for E. coli; streptomycin (Sm) $10 \mu \mathrm{g}$ for E. coli; tetracycline (Tc) $15 \mu \mathrm{g}$ for E. coli and $50 \mu \mathrm{g}$ for Pseudomonas; kanamycin (Km) $100 \mu \mathrm{g}$ for $E$. coli and $400 \mu \mathrm{g}$ for Pseudomonas.

Tn5 mutagenesis. The mutagenesis was done by conjugational transfer of the suicide vector pSUP10141 (pACYC184::Tn5::RP4$T c^{r}$ ) from $E$. coli $\mathrm{S} / 17-1$, which contains genes for plasmid mobilization (Simon et al., 1983). Pseudomonas cells were grown in $3 \mathrm{ml}$ of LB medium at $28^{\circ} \mathrm{C}\left(37^{\circ} \mathrm{C}\right.$ for $P$. aeruginosa $)$ to an $\mathrm{OD}_{600}$ of $0 \cdot 3-0 \cdot 5 ; E$. coli
S17-1(pSUP10141) was similarly grown at $37^{\circ} \mathrm{C}$ in the presence of $\mathrm{Sm}$ (to select for the presence of chromosomally integrated mobilization genes), $\mathrm{Cm}$ (resistance of the vector) and $\mathrm{Km}$ (one of the two resistance genes of $\operatorname{Tn} 5$ ). The Pseudomonas cultures were subsequently kept for $1 \mathrm{~h}$ at $37^{\circ} \mathrm{C}\left(42^{\circ} \mathrm{C}\right.$ for P. aeruginosa $)$ in order to lower the efficiency of the restriction system. Both cultures were centrifuged for $2 \mathrm{~min}$ and washed three times with $\mathrm{LB}$ medium before mixing in $1 \mathrm{ml}$ of LB medium. After a final centrifugation, the mixed cells were resuspended in $50 \mu \mathrm{l}$ of $\mathrm{LB}$ medium. The cells were plated on a sterile nitrocellulose filter put on a pre-warmed LB plate and incubated overnight at $28^{\circ} \mathrm{C}$ ( $37^{\circ} \mathrm{C}$ for $P$. aeruginosa). The cells were washed out of the filter in $10 \mathrm{ml}$ of LB medium and plated undiluted or $10 \times$ diluted on LB plates containing Ap (to counterselect $E$. coli) and $\mathrm{Km}$; control plates were inoculated with the $E$. coli cells or the Pseudomonas cells alone. The plates were incubated for $2 \mathrm{~d}$ at $28^{\circ} \mathrm{C}\left(37^{\circ} \mathrm{C}\right.$ for $P$. aeruginosa).

Tn10 mutagenesis. Plasmid pNK862 is a pBR derivative containing a mini $\mathrm{Tn} 10$ transposon with a $\mathrm{Tn} 903 \mathrm{Km}^{\mathrm{r}}$ gene flanked by the two IS ends of Tn10. The flanking transposase works in cis and does not transpose together with the resistance to $\mathrm{Km}$ (Way et al., 1984). Since the transposase expression depends on the tac promoter, no transposition occurs in E. coli in the absence of IPTG. We decided to introduce this plasmid directly by electroporation into Pseudomonas since the plasmid is not mobilizable (due to deletion of the bom/nic site). Electroporation was done using a Bio-Rad Gene Pulser and Pulse Controller (Smith \& Iglewsky, 1989). Briefly, P. aeruginosa PAOl cells were grown in $\mathrm{LB}$ medium to an $\mathrm{OD}_{600}$ of 0.5 , centrifuged, washed three times in $300 \mathrm{~mm}$-sucrose and concentrated $100 \times$ in the sucrose solution. A $40 \mu \mathrm{l}$ vol. of these cells was mixed with $1 \mu \mathrm{g}$ of the plasmid DNA (pNK862 or pMMB33 as a control) and put on ice. The Gene Pulser was set at $25 \mu \mathrm{F}$ and $1.6 \mathrm{kV}$, and the pulse generated was through a high power $400 \Omega$ resistor. Prechilled cuvettes with $0.2 \mathrm{~cm}$ electrode gaps were used. Directly after electroporation, $1 \mathrm{ml}$ of LB medium was added and the cells were grown for $2 \mathrm{~h}$ at $37^{\circ} \mathrm{C}$ before plating on LB plates containing $\mathrm{Km}$.

Screening of mutants. Mutants were picked with sterile toothpicks and inoculated in MKB medium in Microtiter plates. After $2 \mathrm{~d}$ growth at the appropriate temperature, the plates were examined under $U V$ for fluorescence as an indication of pyoverdine biosynthesis and excretion. Non-fluorescent mutants $\left(\mathrm{Flu}^{-}\right)$were grown in CAA medium $(3 \mathrm{ml})$ and CAA medium containing $0.5 \mathrm{mg}$ EDDHA $\mathrm{ml}^{-1}$.

PCR amplification. A $0.25 \mathrm{~kb}$ fragment corresponding to the open reading frame of the $P$. aeruginosa lipoprotein (Cornelis et al., 1989), which is specific for fluorescent pseudomonads (unpublished results), was amplified in a New Brunswick PCR apparatus using 30 cycles of amplification. Each cycle comprised $1 \mathrm{~min}$ of denaturation at $94^{\circ} \mathrm{C}$, $1 \mathrm{~min}$ of annealing at $60^{\circ} \mathrm{C}$ and $2 \mathrm{~min}$ of elongation at $74^{\circ} \mathrm{C}$. The first primer was a 30-mer extending from the ATG initiation codon and the second was a $21-\mathrm{mer}$, complementary to the end of the open reading frame, extending from the second stop codon.

Southern blots. A $1.6 \mathrm{~kb}$ Sall fragment probe containing part of the $\mathrm{Tc}^{r}$ gene inserted in Tn5 from pSUP10141 was labelled with digoxigenin as described by the manufacturer (Boehringer Mannheim). For the Tn 10 probe, a $1.7 \mathrm{~kb}$ HindIII fragment containing the $\mathrm{Tn} 903$ $\mathrm{Km}^{\mathrm{r}}$ gene was similarly labelled. DNA from the wild-type and mutants was digested with EcoRI or BamHI (for Tn 5 and Tn 10 probes) or with $S m a I$ ( $\operatorname{Tn} 5$ probe); after electrophoresis the DNA was transferred to a nylon membrane (Hybond N). After UV cross-linking, the membrane was prehybridized and hybridized in $5 \times \mathrm{SSC}, 0.5 \%$ blocking reagent from the manufacturer, $0.1 \%$ Sarkosyl and $0.02 \%$ SDS. Washings were done according to the manufacturer's recommendations. Antibody incubation and signal detection with AMPPD (Boehringer Mannheim) were as described by Kreike et al. (1990). 


\section{Results}

Spontaneous Pvd ${ }^{-}$mutants

The level of spontaneous mutants was determined for $P$. aeruginosa PAOL and P. fluorescens ATCC 17400 by analysing 1503 and 987 colonies respectively for their fluorescence on agar CAA medium. No spontaneous $\mathrm{Pvd}^{-}$mutant (lack of fluorescence) could be detected, indicating that the level of spontaneous mutants must be lower than $0 \cdot 1 \%$.

\section{Tn5 mutagenesis}

The results of $\operatorname{Tn} 5$ mutagenesis with the conjugative suicide vector pSUP10141 are summarized in Table 1. The efficiency of transposition per recipient ranged from $1 \cdot 1 \times 10^{-6}$ for $P$. aeruginosa PAO1 to $6 \times 10^{-4}$ for $P$. putida BTP1. The percentage of transconjugants depended on whether or not the cells were pre-incubated at higher temperatures to lower the host restriction system. For PAOl no transconjugants were obtained when the cells were not preincubated for $1 \mathrm{~h}$ at $42^{\circ} \mathrm{C}$ before conjugation. Tn5 mutagenesis yielded no $\mathrm{Flu}^{-}$ mutants in the case of $P$. putida BTP1. For Pseudomas sp. BTP20, $P$. fluorescens 47 and $P$. fluorescens ATCC 17400 the percentage of $\mathrm{Pvd}^{-}$mutants $\left(\mathrm{Flu}^{-}\right.$and $\left.\mathrm{EDDHA}^{-}\right)$ was very similar, ranging from $0.4 \%$ for strain 47 to $0.54 \%$ for ATCC 17400 . This percentage was ten times greater in the case of $P$. chlororaphis $(4 \%)$ and 30 times in the case of $P$. aeruginosa PAO1 $(13 \cdot 1 \%)$, indicating preferential insertion of $\mathrm{Tn} 5$ into the Pvd genes (Hohnadel et al., 1986). Different types of $\mathrm{Pvd}^{-}$mutants were found: $\mathrm{Flu}^{-} \mathrm{EDDHA}^{-}$; $\mathrm{Flu}^{+} \mathrm{EDDHA}^{-}$; and $\mathrm{Flu}^{+}$ only in the presence of EDDHA. These mutants are now being characterized. Only the first type of mutants was found for Pseudomonas strain BTP20; these mutants were very sensitive to EDDHA (results not shown).

Although PAO1 mutants were selected on $400 \mu \mathrm{g} \mathrm{Km}$ $\mathrm{ml}^{-1}$, they rapidly lost this high level of resistance upon subculturing to reach the level of the wild-type $\left(100 \mu \mathrm{g} \mathrm{ml}^{-1}\right)$. This loss of resistance to $\mathrm{Km}$ was paralleled by a similar decrease in resistance to Tc (from $100 \mu \mathrm{g} \mathrm{ml}^{-1}$ to $20 \mu \mathrm{g} \mathrm{ml}^{-1}$ ). However, except for some PAOl mutants, the $\mathrm{Pvd}^{-}$phenotype was very stable. The mutants from other fluorescent pseudomonads were all stable and kept their resistance to both $\mathrm{Km}$ and $\mathrm{Tc}$ even in the absence of selection.

\section{Tn10 mutagenesis}

The Tn 10 mini-Kan plasmid was successfully introduced by electroporation in the two fluorescent pseudomonads

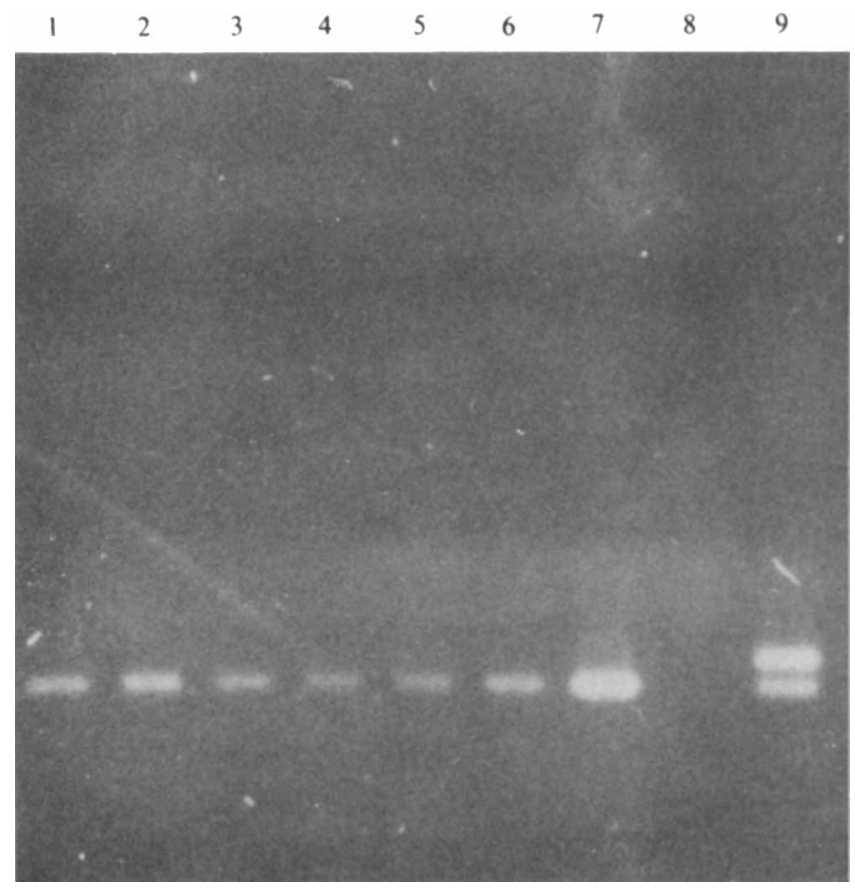

Fig. 1. PCR amplification of the $P$. aeruginosa lipoprotein gene from the DNA of PAO1 Tn10 $\mathrm{Pvd}^{-}$mutants: lane 1, PAO1; lanes 2 to 9, Pvd $^{-}$mutants.

Table 1. Efficiency (per recipient) of Tn5 mutagenesis by conjugational transfer of pSUP10141 into different fluorescent pseudomonads and percentage of Pvd' mutants

\begin{tabular}{lrrr}
\hline \multicolumn{1}{c}{ Strain } & Efficiency & $\begin{array}{c}\text { Pvd }^{-/} \\
\text {no. tested }\end{array}$ & $\begin{array}{r}\text { Percentage } \\
\text { Pvd }^{-}\end{array}$ \\
\hline P. aeruginosa PAO1 & $1 \cdot 14 \times 10^{-6}$ & $50 / 384$ & $13 \cdot 1$ \\
$P$. chlororaphis BTP9 & $2.35 \times 10^{-6}$ & $4 / 96$ & $4 \cdot 16$ \\
$P$. fluorescens 47 & $8 \times 10^{-5}$ & $8 / 1920$ & $0 \cdot 41$ \\
$P$. fluorescens ATCC 17400 & $4 \times 10^{-6}$ & $4 / 764$ & $0 \cdot 52$ \\
$P$. putida BTP1 & $6 \times 10^{-4}$ & $0 / 960$ & 0 \\
Pseudomonas sp. BTP20 & $4.4 \times 10^{-5}$ & $4 / 864$ & 0.46 \\
\hline \hline
\end{tabular}

Table 2. Efficiency of electroporation of pMMB33 and of transposition of Tn10 mini-Kan ( $p N K 862)$ in two Pseudomonas strains

\begin{tabular}{lcr}
\hline \multicolumn{1}{c}{ Strain } & $\begin{array}{c}\text { pMMB33 } \\
\text { (c.f.u. } \mu \mathrm{g}^{-1} \text { ) }\end{array}$ & $\begin{array}{c}\text { Tn } 10 \\
\text { (c.f.u. } \mu \mathrm{g}^{-1} \text { ) }\end{array}$ \\
\hline P. aeruginosa PAO1 & $2 \times 10^{7}$ & $5 \times 10^{3}$ \\
P. fluorescens 47 & $1 \times 10^{6}$ & $2.5 \times 10^{3}$ \\
\hline \hline
\end{tabular}

tested (Table 2). The efficiency of electroporation with the control plasmid pMMB33 was $2 \times 10^{6}$ to $2 \times 10^{7}$ c.f.u. ( $\mu$ g plasmid DNA $)^{-1}$, in good agreement with results obtained by others (Smith \& Iglewsky, 1989). We 


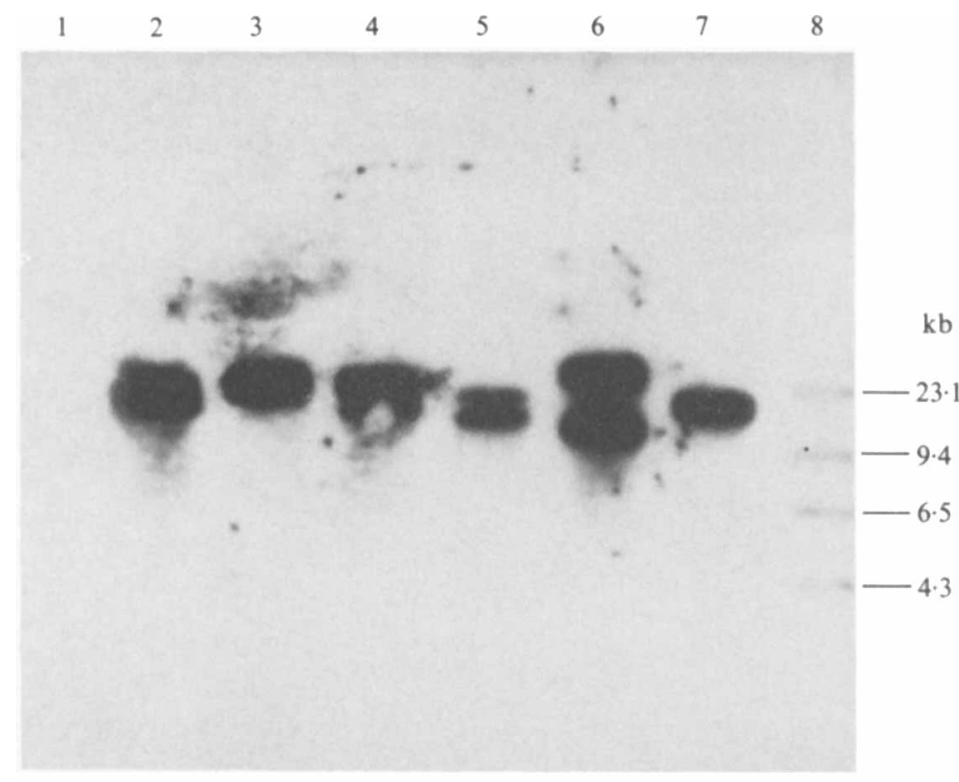

Fig. 2. Detection of $\operatorname{Tn} 5$ insertions in $E c o$ R I-digested DNA from different mutants of $P$. fluorescens ATCC 17440: lane 1, wild-type DNA; lane 2, $\mathrm{Pvd}^{+}$mutant 1G9; lane 3. Pvd ${ }^{-}$mutant 13D4; lane 4, $\mathrm{Pvd}^{-}$mutant $5 \mathrm{Hl}$; lane $5, \mathrm{Pvd}^{-}$mutant $2 \mathrm{G} 11$; lane 6, Pvd- mutant 3G6; lane $7, \mathrm{Pvd}^{+}$mutant $14 \mathrm{H} 10$; lane $8, \lambda$ HindlII, digoxigenin labelled.

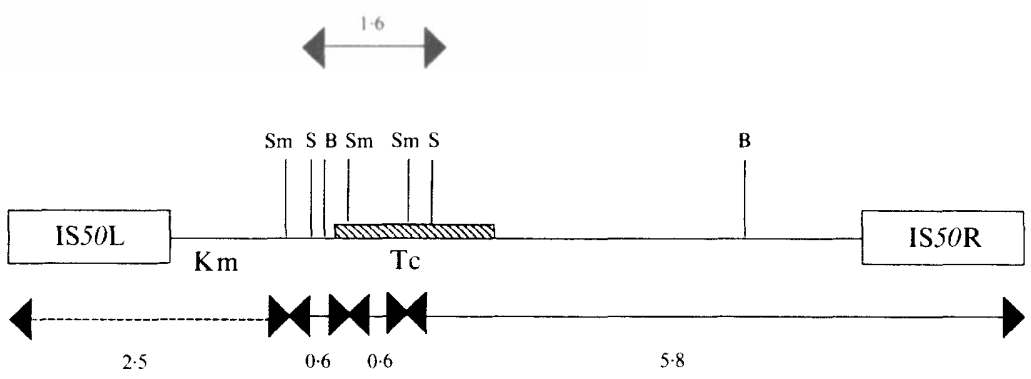

Fig. 3. Map of the transposon Tn5 in pSUP1014l containing the Tc ${ }^{r}$ gene from RP4. The map shows the location of $S m a I(S m)$ and $S a l l$ (S) sites and the sizes of the corresponding fragments in $\mathrm{kb}$. B, BamHI/Sau3A sites. The $1.6 \mathrm{~kb}$ Sall fragment was used as a probe in hydridization experiments. The first fragment on the left (dashed line) was not detected by the probe.

expected a relatively high efficiency of transposition since the tac promoter is efficiently recognized by the RNA polymerase in $P$. aeruginosa (Bagdasarian et al., 1983). The transposition efficiency was similar in both strains ( 2.5 to $5 \times 10^{3}$ c.f.u. $\left.\mu \mathrm{g}^{-1}\right)$. In $P$. aeruginosa, $89 \%$ of the mutants were $\mathrm{Pvd}^{-}$(Flu- EDDHA ${ }^{-}$). In strain 47 (a $P$. fluorescens isolate), all the clones that were resistant to $\mathrm{Km}$ were $\mathrm{Pvd}^{-}$. As for $\mathrm{Tn} 5$ mutagenesis, PAO1 mutants were found to lose their resistance to Km upon subculturing but they retained their $\mathrm{Pvd}^{-}$phenotype.

\section{PCR amplification of the P. aeruginosa lipoprotein gene}

Fig. 1 shows the amplification of the $P$. aeruginosa PAO1 lipoprotein gene in $\mathrm{Tn} 10 \mathrm{Pvd}^{-}$mutants. In all mutants, a fragment of the lipoprotein gene (lpp) of the correct size was amplified except for one Tn10 mutant (lane 8), which was probably a contaminant. Surprisingly, in lane 9, two bands were amplified, one with a molecular mass identical to the control lipoprotein gene and one with a slightly higher molecular mass. As yet, this observation remains unexplained.

\section{Southern blot for the detection of insertions}

Fig. 2 shows the hybridization signals for $\operatorname{Tn} 5$ mutants of $P$. fluorescens ATCC 17400 cut with EcoRI. In $P$. fuorescens ATCC 17400, double insertions were visible in lanes 4, 5 and 6 , corresponding to $\mathrm{Pvd}^{-}$mutants, while single insertions were seen for the non-pyoverdine mutants 1G9 and 14H10 (lanes 2 and 7). For the $\mathrm{Pvd}^{-}$ mutant 13D4 (lane 3), a double band could be seen when the membrane was colour-developed in place of the AMPPD detection (results not shown). Single insertions were also detected in $\mathrm{Pvd}^{-} \mathrm{Tn} 5$ mutants of $P$. chlororaphis and $P$. fluorescens 47 (results not shown). To confirm the double insertions observed in the $P$. fiuorescens ATCC $17400 \mathrm{Pvd}^{-}$mutants, the DNA from these mutants was digested with SmaI, which cuts once in the transposon and twice in the inserted RP4 Tcr gene 


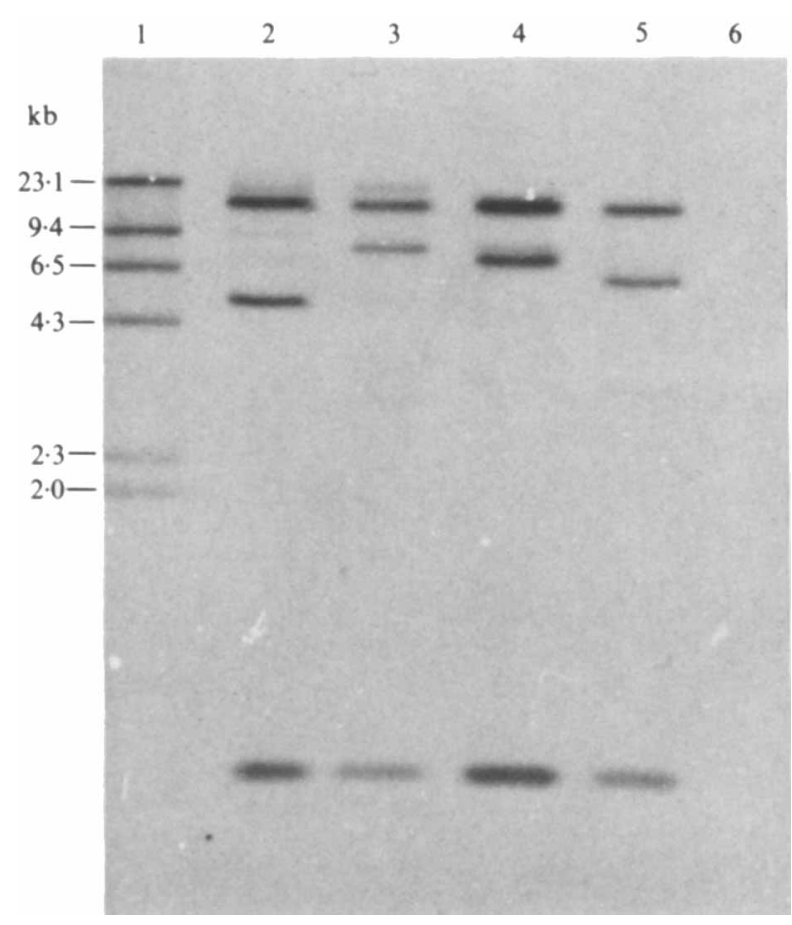

Fig. 4. Confirmation of double Tn 5 insertions in SmaI-digested DNAs from $P$. fluorescens ATCC 17400 Pvd $^{-}$mutants: lane 1, $\lambda$ HindIII, digoxigenin-labelled; lanes 2 to 5 , $\mathrm{Pvd}^{-}$mutants 3G6, 5H1, 2G11, 13D4; lane 6, wild-type.

(Fig. 3). With the $1.6 \mathrm{~kb} \mathrm{Sall}$ fragment probe, which includes part of the $\mathrm{Tc}^{\mathrm{r}}$ gene (Fig. 3), we detected a double band at $0.6 \mathrm{~kb}$, corresponding to the two SmaI fragments in the transposon and two bands, each corresponding to the right-end of the transposon plus adjacent $P$. fluorescens DNA, confirming a double insertion for these four $P$. fluorescens $\mathrm{Pvd}^{-}$mutants (Fig. 4). In Southern blots with PAO1 DNA, we failed to detect any insertion of Tn5 or mini-Kan in the chromosome, confirming the observation that the transposon-borne antibiotic resistance was lost (results not shown).

\section{Discussion}

Tn5 is the most frequently used transposon for mutagenesis of various Gram-negative bacteria, including fluorescent pseudomonads. Tn5 is supposed to insert almost randomly in the genome, although there are reports describing 'hot spots' (Berg et al., 1983; Lodge et al., 1991). Upon insertion, the transposon duplicates $9 \mathrm{bp}$ of the target sequence and analysis of these target sequences has revealed that $\mathrm{Tn} 5$ prefers sequences containing GC pairs at their extremities (Lodge et al., 1988). Other factors such as supercoiling of the DNA may also contribute to a preferential insertion of $\operatorname{Tn} 5$ (Lodge \&
Berg, 1990). In order to study the randomness of $\operatorname{Tn} 5$ insertions in different fluorescent pseudomonads we looked for $\mathrm{Pvd}^{-}$mutations, since these are easy to screen for (absence of fluorescence on iron-limited media such as succinate, King's B or CAA, or lack of growth in the presence of the strong synthetic iron chelator EDDHA). A minimum of 35 genes in five complementation units have been shown to be necessary for the complementation of pseudobactin mutants in P. putida WCS358 (Marugg et al., 1985). Similarly four clusters of 12 genes were found to be a minimum for the complementation of all pseudobactin mutants of the plant-growth-promoting Pseudomonas strain B10 (Moores et al., 1984). If one considers an average of $3 \mathrm{~kb}$ per gene, then a minimum of 105 to $144 \mathrm{~kb}$ would be necessary to contain all the information needed for the biosynthesis of pyoverdine/ pseudobactin. If the size of the $P$. aeruginosa chromosome $(5850 \mathrm{~kb})$ (Holloway et al., 1990; Römling et al., 1989 ) is taken as representative of the chromosome size of other fluorescent pseudomonads, then random insertions of $\mathrm{Tn} 5$ would yield about 1.8 to $2.5 \% \mathrm{Pvd}^{-}$mutants. By UV or chemical mutagenesis of $P$. aeruginosa PAO1, Hohnadel et al. (1986) found about $0 \cdot 2 \% \mathrm{Pvd}^{-}$mutants, but their selection was based only on the absence of fluorescence. This low percentage of $\mathrm{Pvd}^{-}$mutants after UV mutagenesis is an indication that the level of spontaneous mutants must be very low, precluding any possibility that our PAO1 $\mathrm{Pvd}^{-}$mutants could be spontaneous. We found that some mutants were $\mathrm{Flu}^{+} \mathrm{EDDHA}^{-}$; we consider that these could be deficient in the synthesis of the peptide arm of the siderophore or in the uptake of ferripyoverdine (unpublished results). The percentages of $\mathrm{Pvd}^{-}$mutants for $P$. fluorescens ATCC $17400, P$. fluorescens 47 and Pseudomonas sp. BTP20 were in good agreement with this prediction, and could be interpreted as the result of a random insertion of Tn5 in the chromosome. Single Tn5 insertions were observed in all fluorescent pseudomonads examined except in $P$. fluorescens ATCC $17400 \mathrm{Pvd}^{-}$mutants, where double insertions were detected in all mutants tested. Non-pyoverdine mutants, however, contained only single insertions. To our knowledge, such a phenomenon has never been described before. No Pvd ${ }^{-}$ mutants could be detected after mutagenesis of $P$. putida BTP1, although a total of 1865 mutants were tested and replicated on MKB and MKB EDDHA medium, indicating a lower frequency of insertion of $\operatorname{Tn} 5$ in this region. Slightly higher than expected values were obtained for $P$. chlororaphis BTP9 $\left(4 \% \mathrm{Pvd}^{-}\right.$mutants or about twice the expected value) and especially for $P$. aeruginosa PAO1 $(13 \%$ or about five times the expected value and twenty times the value observed for other strains). These results suggest that, in $P$. aeruginosa, $\mathrm{Tn} 5$ inserts preferentially into one region where clusters of 
pyoverdine biosynthesis and/or regulation genes are present. Pvd mutations could be mapped in two regions of the chromosome of $P$. aeruginosa PAO1: one locus is in the $35^{\prime}$ region between $\arg C$ and $\operatorname{str} A$, and the other one is in the $65^{\prime}$ region between cat $A$ and $m t u-9002$ (Hohnadel et al., 1986). In the new recalibrated map of the PAO1 chromosome, these two loci would be at $25^{\prime}$ and $45-50^{\prime}$ respectively (O’Hoy \& Krishnapillai, 1987). Krishnapillai et al. (1981) described the preferential insertions of transposon $\operatorname{Tn} I$ into the same 60-65' region (old map) in the PAOl chromosome. Tn 5 was found to be stable in the fluorescent pseudomonads examined except in PAO1, where it was rapidly lost. Excision of Tn5 has already been described in E. coli (Egner \& Berg, 1981). Two types of excisions can be distinguished: precise excision where the target 9 bp DNA repetition is also excised, and imprecise excision, where the target repetition remains, together with some transposon DNA (Lundblad et al., 1984). In the first case the mutation reverts to the wild-type, in the second, it does not. The frequency of the two events in $E$. coli was found to be $10^{-6}$ for precise excision and $10^{-5}$ for imprecise excision of $\mathrm{Tn} 5$ from the lac gene in a $\mathrm{F}^{\prime}$ lac strain (Egner \& Berg, 1981). In some $P$. aeruginosa strains, including PAO1, Tn5 was found to be unstable (Stapleton et al., 1984; Goldberg et al., 1990), while in others the transposon was stably maintained (Höfte et al., 1991). Goldberg et al. (1990) described the high frequency $\left(10^{-3}\right)$ precise excision of Tn 5 from plasmid DNA when this plasmid was transferred to PAO1. The mechanism of excision is poorly understood but is independent of the transposase and of the host RecA protein (Egner \& Berg, 1981; Goldberg et al., 1990). However, the terminal inverted repeats of the transposon seem to play an important role in this process (Lundblad et al., 1984; Goldberg et al., 1990). Mutations in alleles of RecBC were also found to increase the rate of excision in E. coli (Lundblad et al., 1984). In our case, the transposon was found to excise almost completely since resistances to both $\mathrm{Km}$ and $\mathrm{Tc}$ were lost and no signal was found in hybridization experiments, even when the whole transposon was used as a probe (results not shown). However, with the exception of a few mutants, the rate of reversion was low indicating that imprecise excision occurred or that the transposon caused deletions in the chromosome.

We successfully introduced the Tn 10 ptac mini-Kan into PAOl and P. fluorescens 47. To our great surprise, $89 \%$ of the $\mathrm{Km}^{\mathrm{r}}$ clones were $\mathrm{Pvd}^{-}$in the case of $P$. aeruginosa and $100 \%$ in the case of $P$. fluorescens 47 . PCR amplification of the $P$. aeruginosa lipoprotein gene for the $P$. aeruginosa mutants confirmed, however, that all but one were $P$. aeruginosa.

We conclude that pyoverdine gene cluster(s) can be hot spots for transposon insertion in some fluorescent pseudomonads and that care should be taken to control the stability of a given transposon in fluorescent pseudomonads.

This research is funded by the Belgian Nationaal Fonds voor Wetenschappelijke Onderzoek/Fonds National de la Recherche Scientifique (NFWO/FNRS). We wish to thank Samson Muyanga and Xaphanaiah Muunga for their help at the beginning of this work.

\section{References}

Bagdasarian, M. M., Amann, E., Lurz, R., Rückert, B. \& Bagdasarian, M. (1983). Activity of the hybrid trp-lac (tac) promoter of Escherichia coli in Pseudomonas putida. Construction of broad-host-range, controlled expression vectors. Gene 26, 273-282.

BERG, D. E. (1977). Insertion and excision of the transposable kanamycin resistance determinant Tn5. In DNA Insertion Elements, Plasmids and Episomes, pp. 205-212. Edited by A. I. Bukhari, J. A. Shapiro \& S. L. Adhya. Cold Spring Harbor, NY: Cold Spring Harbor Laboratory.

Berg, D. E. \& Berg, C. M. (1983). The prokaryotic transposable element Tn5. Bio/Technology 1, 417-435.

Berg, D. E., Schmandt, M. A. \& Lowe, J. B. (1983). Specificity of transposon Tn 5 insertion. Genetics 105, 813-828.

Cornelis, P., Bouia, A., Belarbi, A., Guyonvarch, A., Kammerer, B., Hannaert, V. \& Hubert, J. C. (1989). Cloning and analysis of the gene for the major outer membrane lipoprotein from Pseudomonas aeruginosa. Molecular Microbiology 3, 421-428.

EGNER, C. \& BerG, D. E. (1981). Excision of transposon Tn5 is dependent on the inverted repeats but not on the transposase function of Tn5. Proceedings of the National Academy of Sciences of the United States of America 78, 459-463.

Frey, J., Bagdasarian, M., Feiss, D., Franklin, F. C. \& Deshusses, J. (1983). Stable cosmid vectors that enable the introduction of cloned fragments into a wide range of Gram-negative bacteria. Gene 24, 299-308.

Goldberg, J. B., Won, J. \& Ohman, D. E. (1990). Precise excision and instability of the transposon $\mathrm{Tn} 5$ in Pseudomonas aeruginosa. Journal of General Microbiology 136, 789-796.

Höfte, M., Seong, K. Y., Jurkevitch, E. \& Verstraete, W. (1991). Pyoverdin production by the plant-growth-beneficial Pseudomonas strain 7NSK2: ecological significance in soil. Plant and Soil 130, 249-257.

Hohnadel, D. \& MeYer, J. M. (1988). Specificity of pyoverdinemediated iron uptake among fluorescent Pseudomonas strains. Journal of Bacteriology 170, 4865-4873.

Hohnadel, D., HaAs, D. \& MeYer, J. M. (1986). Mapping of mutations affecting pyoverdine production in Pseudomonas aeruginosa. FEMS Microbiology Letters 36, 195-199.

Holloway, B. W., Dharmsthiti, S., Johnson, C., Kearney, A., Krishnapillai, V., Morgan, A. F., Ratnaningsih, E., Saffery, R., Sinclair, M., Strom, D. \& Zhang, C. (1990). Chromosome organization in Pseudomonas aeruginosa and Pseudomonas putida. In Pseudomonas: Biotransformation, Pathogenesis, and Evolving Biotechnology, pp. 269-278. Edited by S. Silver, A. M. Chakrabarty, B. Iglewski \& S. Kaplan. Washington, DC: American Society for Microbiology.

KLECKNER, N. (1981). Transposable elements in prokaryotes. Annual Review of Genetics 15, 341-404.

Kreike, C. M., DE Koning, J. R. A. \& Krem, F. A. (1990). Nonradioactive detection of single-copy DNA-DNA hybrids. Plant Molecular Biology Reports 8, 172-179.

Krishnapillai, V., RoYle, P. \& LeHReR, J. (1981). Insertions of the transposon $\mathrm{Tn} I$ into the Pseudomonas aeruginosa chromosome. Genetics 97, 495-511.

LEONG, J. (1986). Siderophores: their biochemistry and possible role in the biocontrol of plant pathogens. Annual Review of Phytopathology 24, 187-209. 
LODGe, J. K., Weston-Hafer, K. \& Berg, D. E. (1988). Transposon $\mathrm{Tn} 5$ target specificity: preference for insertion at $\mathrm{G} / \mathrm{C}$ pairs. Genetics 120, 645-650.

LODGE, J. K. \& BERG, D. E. (1990). Mutations that affect Tn 5 insertion into the major Tn5 hotspot in pBR322: importance of local DNA supercoiling. Journal of Bacteriology 172, 5956-5960.

LODGE, J. K., Weston-HAFER, K. \& BeRG, D. E. (1991). Tn5 insertion specificity is not influenced by IS50 end sequences in target DNA. Molecular and General Genetics 228, 312-315.

Lundblad, V., TayloR, A. F., Smith, G. R. \& Kleckner, N. (1984). Unusual alleles of RecB and RecC stimulate excision of inverted repeat transposons $\operatorname{Tn} 10$ and Tn5. Proceedings of the National Academy of Sciences of the United States of America 81, 824-828.

Marugg, J. D., van Spanje, M., Hoeksta, W. P., Schippers, B. \& WEISBEEK, P. (1985). Isolation and analysis of genes involved in siderophore biosynthesis in plant-growth-stimulating Pseudomonas putida WCS358. Journal of Bacteriology 164, 563-570.

Moores, J. C., Magazin, M., DitTa, G. S. \& Leong, J. (1984). Cloning of genes involved in the biosynthesis of pseudobactin, a high-affinity iron transport agent of a plant growth-promoting Pseudomonas strain. Journal of Bacteriology 157, 53-58.

O'HoY, K. \& KRIShnapillai, V. (1987). Recalibration of the Pseudomonas aeruginosa strain PAO chromosome map in time units using high-frequency-of-recombination donors. Genetics 115, 611618.
O'Sullivan, D. J. \& O'Gara, F. (1990). Iron regulation of ferric iron uptake in a fluorescent pseudomonad: cloning of a regulatory gene. Molecular Plant-Microbe Interactions 3, 86-93.

Römling, U., Grothues, D., BaUTSCH, W. \& TÜMMLER, B. (1989). A physical genome map of Pseudomonas aeruginosa. EMBO Journal 8 , 4081-4089.

Simon, R., Priefer, U. \& Pühler, A. (1983). A broad host range mobilization system for in vivo genetic engineering: transposon mutagenesis in Gram-negative bacteria. Bio/Technology 1, 784-791.

SMITH, A. W. \& IglewSKY, B. H. (1989). Transformation of Pseudomonas aeruginosa by electroporation. Nucleic Acids Research 17, 10509.

Stapleton, M. J., JAGGer, K. S. \& WARREN, R. I. (1984). Transposon mutagenesis of Pseudomonas aeruginosa exoprotease genes. Journal of Bacteriology 157, 7-12.

Way, J. C., Davis, M. A., Morisato, D., RoberTs, D. E. \& KLECKNer, N. (1984). New Tn 10 derivatives for transposon mutagenesis and for construction of lac $Z$ operon fusions by transposition. Gene 32, 369379.

Wendenbaum, S., Demange, P., Dell, A., Meyer, J. M. \& AbDallaH, M. A. (1983). The structure of pyoverdine $P a$, the siderophore of Pseudomonas aeruginosa. Tetrahedron Letters 24 , $4877-4880$. 